\title{
PRODUTIVIDADE DE CULTIVARES DE SOJA SUBMETIDAS A DIFERENTES POPULAÇÕES DE PLANTAS NA REGIÃO DA NOVA ALTA PAULISTA
}

\author{
NAKAYAMA, Fernando Takayuki ${ }^{1}$; SILVA, Lucas de Souza ${ }^{2}$; SANTOS, Guilherme Xavier Lúcio dos ${ }^{3}$; \\ CORDEIRO JUNIOR, Paulo Sergio ${ }^{4}$; DONÁ, Sérgio ${ }^{5}$; FINOTO, Everton Luis ${ }^{6}$; BRANDÃO, Rebeca \\ Pereira $^{2}$; OLIVEIRA, Loyara Joice ${ }^{7}$; CORDEIRO, Cicero $^{8}$
}

ISSUE DOI: $10.3738 / 1982.2278 .3632$

\begin{abstract}
RESUMO: A cultura da soja vem ganhando importância no estado de São Paulo, principalmente para a região Oeste Paulista, onde se tornou uma opção muito interessante na rotação de cultura principalmente em áreas de reforma de canaviais e pastagens, pelos benefícios que a mesma propõe ao solo como fixação simbiótica de $\mathrm{N}$ e rentabilidade. Neste contexto, medidas como escolha de variedades, e estudos com densidade populacional pode trazer informações imprescindíveis para produtores, já que o potencial produtivo das cultivares é diretamente dependente das características edafoclimáticas regionais. O presente trabalho foi conduzido durante o ano agrícola 2018/19, na APTA/PR Alta Paulista em Adamantina-SP com o plantio realizado em 15 de outubro e colheita 05 de fevereiro, tendo como materiais avaliados as variedades NS5909; Precoz; M7739 e M5917. Foram avaliadas diâmetro de caule $(\mathrm{mm})$, altura de plantas $(\mathrm{m})$, número de trifólios, massa de 100 grãos e produtividade $\left(\mathrm{kg} \mathrm{ha}^{-1}\right)$. De acordo como os resultados obtidos as variedades estudadas apresentaram diferentes comportamentos e produtividades para a região da Alta Paulista; As variedades M5917, M7739 e NS5909 não apresentaram diferenças para produtividade de grãos; A cultivar PRECOZ expressa o seu melhor potencial produtivo com a população de 222 mil plantas. ha ${ }^{-1}$.
\end{abstract}

Palavras-Chave: Glicine max. Densidade de semeadura. Produtividade de grãos.

\section{SOYBEAN CULTIVARS PRODUCTIVITY SUBMITTED TO DIFFERENT PLANT POPULATIONS IN NEW ALTA PAULISTA REGION}

\begin{abstract}
SUMMARY: The soybean crop has been of great importance for São Paulo State and related, especially for Oeste Paulista region, where it exerts a option in crop rotation mainly in areas of cane and pasture, for the benefits that it proposes to the soil with symbiotic $\mathrm{N}$ fixation and profitability. In this context, measures such as variety selection and population density studies can bring important information to producers, since the productive potential of the cultivars is directly dependent on the regional edaphoclimatic characteristics. The present work was conducted during the agricultural year of 2018/19, at the research farm belonging to the APTA / PR Alta Paulista in Adamantina-SP with the planting carried out on October 15 and harvest February 5, having evaluated the varieties NS5909; PRECOZ; M7739 and M5917. Stem diameter (mm), plant height (m), number of leaf, mass of 100 grains and yield $\left(\mathrm{kg} \cdot \mathrm{ha}^{-1}\right)$ were evaluated. According to the results obtained, the varieties studied in the present study presented different behaviors and productivity for the region of Alta Paulista; The varieties M5917, M7739 and NS5909 did not show differences for grain yield; For productivity of the PRECOZ, the population of 222 plants.ha $^{-1}$.
\end{abstract}

Keywords: Glicine max. Density of sowing. Yield grains.

\footnotetext{
${ }^{1}$ Pesquisador Cientifico, Dr. - PRDTA Alta Paulista, Adamantina, SP;

${ }^{2}$ Graduando em Agronomia - Centro Universitário de Adamantina - UNIFAI, Adamantina SP;

${ }^{3}$ Engenheiro Agrônomo, Bolsista de Aperfeiçoamento Técnico FUNDAG/APTA/SAA - PRDTA Centro Norte, Pindorama, SP;

${ }^{4}$ Mestrando em Produção Vegetal - FCAV-UNESP, Jaboticabal, SP;

${ }^{5}$ Pesquisador Cientifico, Msc - PRDTA Médio Paranapanema, Assis, SP;

${ }^{6}$ Pesquisador Cientifico, Dr. - PRDTA Centro Norte, Pindorama, SP;

${ }^{7}$ Graduanda em Agronomia - Universidade Estadual Paulista - UNESP, Dracena, SP;

${ }^{8}$ Assistente Técnico de Pesquisa - PRDTA Alta Paulista, Adamantina, SP.
} 


\section{INTRODUÇÃO}

A implantação da soja Glyine max (L.) na agricultura brasileira ocasionou uma grande revolução no setor, uma cultura inicialmente incipiente, tornou-se em curto período uma das principais culturas (grãos) de exploração agrícola e de importância economia nacional. O Brasil é o segundo maior produtor mundial de soja, atrás apenas dos EUA. Na safra 2016/2017, a cultura ocupou uma área de 33,89 milhões de hectares, o que totalizou uma produção de 113,92 milhões de toneladas. A produtividade média da soja brasileira foi de $3.362 \mathrm{~kg}$ por hectare. (EMBRAPA, 2017).

A cultura da soja vem ganhando importância no estado de São Paulo, principalmente para a região Oeste Paulista, onde se tornou uma opção muito interessante na rotação de cultura principalmente em áreas de reforma de canaviais e pastagens, pelos benefícios que a mesma propõe ao solo como fixação simbiótica de $\mathrm{N}$ e rentabilidade. Outrora cultivada principalmente nos Estados de Mato Grosso, Goiás, Mato Grosso do Sul e afins, vem cada vez mais ganhando espaço no território paulista devido inúmeros fatores benéfico que a cultura traz a seus produtores.

Neste contexto, medidas como escolha de cultivares e estudos com densidade populacional pode trazer informações imprescindíveis para os produtores, já que o potencial produtivo das cultivares é diretamente dependente das características edafoclimáticas regionais. A qualidade do solo, localização geográfica e outros fatores podem afetar as características da planta, incluindo a densidade populacional (MARCOS FILHO, 1986; EMBRAPA, 1993)

A densidade de semeadura tem sido um fator muito crítico quando o assunto tratado é a produtividade final, principalmente para a região em questão, uma vez que o foco do produtor de soja é também o retorno econômico que a cultura trará. Outros fatores devem ser levados em consideração para a decisão de qual densidade populacional usar, tais como a finalidade do seu plantio, se é somente como rotação de culturas ou se o objetivo maior é de fato a extração de grãos. O presente trabalho teve o objetivo de estudar o comportamento de 4 variedades de soja indicados para a região da Nova Alta Paulista, bem como encontrar o melhor população de plantas para as mesmas.

\section{MATERIAL E MÉTODO}

O experimento foi conduzido no Polo Regional de Desenvolvimento Tecnológico dos Agronegócios da Alta Paulista, da Agência Paulista de Tecnologia dos Agronegócios - APTA, localizado no município de Adamantina, SP. O clima da região é classificado, segundo Köppen como AW, definido como tropical úmido com pluviosidades mais elevadas no verão e seca no inverno. A altitude do local é de 453 metros. O solo local é classificado como Argissolo vermelho/amarelo eutrófico a moderado, com uma textura média / arenosa e apresenta uma topografia mais ondulada (EMBRAPA, 1999).

A região da Nova Alta Paulista possui um clima tropical úmido, com pluviosidades mais significantes no verão. O município em que se devolveu a presente pesquisa possui índice médio anual de chuva de aproximadamente $1400 \mathrm{~mm}$ (CIIAGRO, 2019).

A pesquisa foi conduzida durante o ano agrícola de 2018/19, com a semeadura realizada em 15 de outubro e colheita 05 de fevereiro, tendo como materiais avaliados as variedades NS5909; Precoz; M7739 e M5917.

As características químicas do solo antes da implantação do experimento apresentaram os valores descritos na Tabela 1. 
Tabela 1. Análise química do solo da área do experimento, Adamantina 2018.

\begin{tabular}{llllllllllll}
\hline $\begin{array}{l}\mathrm{pH} \\
\left(\mathrm{CaCl}_{2}\right)\end{array}$ & $\begin{array}{l}\mathrm{MO} \\
\left(\mathrm{g} \mathrm{dm}^{-3}\right)\end{array}$ & $\begin{array}{l}\mathrm{P} \\
\mathrm{mg} \mathrm{dm}^{-3}\end{array}$ & $\mathrm{~K}$ & $\mathrm{Ca}$ & $\mathrm{Mg}$ & $\mathrm{H}+\mathrm{Al}$ & $\mathrm{Al}$ & $\mathrm{SB}$ & $\mathrm{T}$ & $\mathrm{V} \%$ & $\mathrm{~m} \%$ \\
\hline 4.6 & 12.0 & 26.0 & 2.9 & 8.0 & 4.0 & 20.0 & 1.0 & 14.9 & 34.9 & 43.0 & 6.0 \\
\hline
\end{tabular}

SB: Soma das bases; V\%: Saturação por bases; m\%: saturação por alumínio; T: capacidade de troca catiônica

Setenta dias antecedendo a semeadura, a saturação por bases foi elevada a $65 \%$ com aplicação de calcário, seguindo recomendações do Boletim Técnico 100 (RAIJ, 1987).

Imediatamente antes da semeadura, as sementes foram submetidas à inoculação com estirpes de Bradyrhizobium japonicum e coinoculadas com estirpes de Azospirillum brasilense nas doses recomendadas do produto comercial.. A semeadura do experimento ocorreu no dia 15/10/2018 em sistema de semeadura direta, utilizando-se o adubo formulado 08-40-00, na dose recomendada pelo Boletim Técnico 100 (RAIJ, 1987).

O delineamento experimental empregado foi o de blocos ao acaso com quatro repetições. No ato da instalação, foram semeadas 14 sementes por metro linear, espaçados $0,45 \mathrm{~m}$ entre linhas. Para o estudo de população, foi realizado o desbaste de plantas quinze dias após a emergência, obtendo parcelas com tratamentos de 6,8,10 e 12 plantas por metro linear. O tamanho das parcelas foi de 5 metros de comprimento com cinco linhas de plantio, sendo duas destas consideradas como bordaduras, obtendo uma área útil de avaliação de $6,75 \mathrm{~m}^{2}$ por parcela, que posteriormente transformada para ha.

As variáveis analisadas no presente trabalho foram: diâmetro de caule $(\mathrm{mm})$ obtido através de paquímetro, número de trifólios, altura de plantas (m) utilizando trena, massa de 100 grãos (g) e produtividade $\left(\mathrm{kg} \mathrm{ha}^{-1}\right)$. As variáveis biométricas foram realizadas a 30 dias antes da colheita. Todo o processo de colheita foi realizado a mão, $O$ material coletado foi beneficiado separadas em sacos de papel e pesadas em balança digital de pêndulo e balança digital de mesa para obter os resultados de massa de colheita, assim foram separados 100 grãos totalmente ao acaso de cada variedade e pesados separadamente também em balança digital. Padronizou-se umidade média de $13 \%$ para a realização das avaliações de produtividade.

Os dados coletados no presente experimento foram submetidos a análise de variância através do teste $\mathrm{F}$ e quando significativas, as médias foram comparadas pelo teste Tukey a 5\% de probabilidade.

\section{RESULTADO E DISCUSSÃO}

Na Tabela 2 constam as características agronômicas da variedade M5917. Verifica-se que para as variáveis: diâmetro caulinar, altura de plantas e número de trifólios, não houve diferença significativa entre os tratamentos. Ao nível de campo, em avaliação visual não foi possível identificar diferenças visuais entre os tratamentos. Observando os resultados, pode-se afirmar que para esta variedade o estande populacional não é um fator limitante que pode influenciar na produtividade final. Fato este pode estar atribuído à arquitetura da planta, que nestas condições climáticas a variedade compensou o espaço entre plantas e possivelmente produziu maior ramificação equilibrando a produção de vagens de forma compensatória. Para variedades como esta, o aumento da densidade além da faixa indicada pelos obtentores, demonstra ser uma prática desnecessária, pois não confere ganhos significativos de produtividade, concordando com Balbinot Junior et al. (2015). 
Tabela 2 - Médias dos parâmetros: diâmetro caulinar $(\mathrm{cm})$, altura de planta $(\mathrm{cm})$, número de trifólios, massa de 100 grãos (g) e produtividade $\left(\mathrm{kg} \mathrm{ha}^{-1}\right.$ ) (umidade 13\%) obtidos em soja variedade M5917 conduzidos em sistema de semeadura direta. Adamantina, SP. Safra 2018/2019.

\begin{tabular}{lccccc}
\hline Avaliações & $\begin{array}{c}\text { Diâmetro } \\
\text { caulinar }\end{array}$ & $\begin{array}{c}\text { Altura de } \\
\text { planta }\end{array}$ & $\begin{array}{c}\text { Número de } \\
\text { trifólios }\end{array}$ & $\begin{array}{c}\text { Massa de } \\
\mathbf{1 0 0} \text { grãos }\end{array}$ & Produtividade \\
\hline Teste F & 0,40 & 1,23 & 0,98 & 1,43 & 0,80 \\
CV\% & 6,39 & 2,04 & 3,99 & 6,25 & 10,11 \\
D.M.S. & 1,15 & 2,24 & 2,03 & 2,41 & 386,68 \\
\hline T1 -6 & $8,11 \mathrm{a}$ & $50,01 \mathrm{a}$ & $23,61 \mathrm{a}$ & $18,11 \mathrm{a}$ & $1.703,00 \mathrm{a}$ \\
T2 -8 & $8,04 \mathrm{a}$ & $50,59 \mathrm{a}$ & $23,05 \mathrm{a}$ & $17,33 \mathrm{a}$ & $1.746,25 \mathrm{a}$ \\
T3 -10 & $8,42 \mathrm{a}$ & $49,27 \mathrm{a}$ & $22,85 \mathrm{a}$ & $17,77 \mathrm{a}$ & $1.833,00 \mathrm{a}$ \\
T4 -12 & $8,20 \mathrm{a}$ & $49,65 \mathrm{a}$ & $22,53 \mathrm{a}$ & $16,60 \mathrm{a}$ & $1.646,75 \mathrm{a}$ \\
\hline
\end{tabular}

As médias seguidas pela mesma letra minúscula na coluna não diferem estatisticamente entre si pelo Teste de Tukey ao nível de $5 \%$ de probabilidade.

Nas análises de dados da cultivar PRECOZ, não foram identificadas diferenças significativas para altura de planta e número de trifólio, mas diferiram estatisticamente nas variáveis de diâmetro caulinar e produtividade final que podem ser observado na tabela 03. Para a variável de diâmetro caulinar, o melhor resultado obtido partiu da densidade populacional de 6 plantas finais por metro, apresentando diâmetro médio de $8,31 \mathrm{~cm}$. Já em termos de produtividade, a densidade populacional de 6 plantas apresentou o menor resultado, que tornou possível a observação de que para essa variedade, a densidade populacional de 6 plantas finais não trará incremento na produtividade de grãos, pois ela apresentou um bom desenvolvimento caulinar mas não produziu o necessário para superar a produtividade das demais densidades, enquanto a densidade final de 10 plantas apresentou o melhor resultado de produtividade. Fato este pode estar atribuído à característica arquitetônica da variedade, se comportando de forma mais ereta e desta forma apresentando maior produtividade nos estandes de 8 a 10 plantas por metro linear, ou 220 mil plantas por hectare nas condições edafoclimáticas do local do experimento. Os presentes resultados concordam com Tourino et al. (2002), que concluíram que a produtividade da soja aumenta com a redução do espaçamento entre linhas aliado à redução da densidade de plantas nas linhas sendo que o espaçamento de $45 \mathrm{~cm}$ com a densidade de 10 plantas $\mathrm{m}^{-1}$ proporcionou a melhor distribuição das plantas na área, permitindo, graças às alterações na sua arquitetura, um maior fechamento das entre linhas.

Tabela 3 - Dados da cultivar PRECOZ, médias de diâmetro caulinar $(\mathrm{cm})$, altura de planta $(\mathrm{cm})$, número de trifólios, massa de 100 grãos (g) e produtividade $\left(\mathrm{kgha}^{-1}\right)$ (umidade 13\%) conduzidos em sistema de semeadura direta. Adamantina, SP. Safra 2018/ 2019.

\begin{tabular}{lccccc}
\hline Avaliações & $\begin{array}{c}\text { Diâmetro } \\
\text { caulinar }\end{array}$ & $\begin{array}{c}\text { Altura de } \\
\text { planta }\end{array}$ & $\begin{array}{c}\text { Número de } \\
\text { trifólios }\end{array}$ & $\begin{array}{c}\text { Massa de } \\
\mathbf{1 0 0} \text { grãos }\end{array}$ & Produtividade \\
\hline Teste F & & & $4,43^{*}$ & 1,11 & $27,27 * *$ \\
CV\% & & & 8,06 & 7,02 & 5,16 \\
D.M.S. & & & 1,38 & 6,94 & 178,80 \\
\hline T1 -6 & $8,31 \mathrm{a}$ & $44,88 \mathrm{a}$ & $21,94 \mathrm{a}$ & $15,84 \mathrm{a}$ & $1.275,75 \mathrm{c}$ \\
$\mathrm{T} 2-8$ & $6,80 \mathrm{~b}$ & $47,04 \mathrm{a}$ & $19,19 \mathrm{a}$ & $16,58 \mathrm{a}$ & $1.649,00 \mathrm{ab}$ \\
$\mathrm{T} 3-10$ & $7,85 \mathrm{ab}$ & $43,20 \mathrm{a}$ & $18,55 \mathrm{a}$ & $17,18 \mathrm{a}$ & $1.773,25 \mathrm{a}$ \\
$\mathrm{T} 4-12$ & $8,03 \mathrm{ab}$ & $44,00 \mathrm{a}$ & $20,89 \mathrm{a}$ & $17,14 \mathrm{a}$ & $1.575,75 \mathrm{~b}$ \\
\hline
\end{tabular}

As médias seguidas pela mesma letra minúscula na coluna não diferem estatisticamente entre si pelo Teste de Tukey ao nível de 5\% de probabilidade. 
Para a cultivar de soja M7739 foram e detectadas diferenças significativas para as variáveis Altura de Plantas e Massa de 100 grãos. De acordo com os resultados obtidos observa-se que as populações de 10 e 12 plantas por metro superaram em altura de plantas a população de 6 plantas por metro, o que pode ser explicado pela característica de crescimento e comportamento arquitetônico da planta na fase vegetativa. É considerado natural que nas mesmas condições de ambiente, a planta acaba se comportando de forma vertical pois o fototropismo se evidencia. Porém quando observado a produtividade, não foram encontradas diferenças. Neste caso pode se afirmar que a planta pode ter compensado em emissão de ramos laterais, não diferindo na produtividade. Já para massa de 100 grãos, observou-se diferenças, em que as populações de 10 e 12 plantas por metro produziram grãos mais densos que 6 e 8 plantas, concordando com Peixoto (1998) que também encontrou acréscimos na massa de 100 grãos com o aumento da densidade. Segundo vários autores, com o aumento da densidade de plantas há tendência de haver maior aprofundamento das raízes e, por isso, há maior capacidade de absorção de água na camada subsuperficial do solo, permitindo suprimento hídrico mais adequado às plantas na fase de enchimento de grãos. (PROCÓPIO et al., 2014). Nesse sentido, pode afirmar que para a finalidade de produção de sementes, possivelmente as populações de 10 e 12 plantas pode ser mais interessante.

Tabela 4 - Análise dos dados da cultivar M7739, dados médios de diâmetro caulinar $(\mathrm{cm})$, altura de planta $(\mathrm{cm})$, número de trifólios, massa de 100 grãos $(\mathrm{g})$ e produtividade $\left(\mathrm{kg} \mathrm{ha}^{-1}\right)$ (umidade 13\%) conduzidos em sistema de semeadura direta. Adamantina, SP. Safra 2018/2019.

\begin{tabular}{lccccc}
\hline Avaliações & $\begin{array}{c}\text { Diâmetro } \\
\text { caulinar }\end{array}$ & $\begin{array}{c}\text { Altura de } \\
\text { planta }\end{array}$ & $\begin{array}{c}\text { Número de } \\
\text { trifólios }\end{array}$ & $\begin{array}{c}\text { Massa de } \\
\text { 100 grãos }\end{array}$ & Produtividade \\
\hline Teste F & 1,00 & $3,91^{*}$ & 0,18 & $24,50^{* *}$ & 0,87 \\
CV\% & 4,10 & 3,86 & 7,68 & 3,05 & 14,07 \\
D.M.S. & 0,77 & 4,36 & 3,93 & 1,11 & 448,04 \\
\hline T1 -6 & $8,42 \mathrm{a}$ & $48,50 \mathrm{~b}$ & $23,50 \mathrm{a}$ & $15,34 \mathrm{~b}$ & $1.419,75 \mathrm{a}$ \\
T2 -8 & $8,36 \mathrm{a}$ & $51,00 \mathrm{ab}$ & $23,50 \mathrm{a}$ & $15,88 \mathrm{~b}$ & $1.344,75 \mathrm{a}$ \\
T3 -10 & $8,59 \mathrm{a}$ & $52,75 \mathrm{a}$ & $23,00 \mathrm{a}$ & $17,21 \mathrm{a}$ & $1.571,75 \mathrm{a}$ \\
T4 -12 & $8,74 \mathrm{a}$ & $52,50 \mathrm{a}$ & $22,75 \mathrm{a}$ & $17,88 \mathrm{a}$ & $1.432,50 \mathrm{a}$
\end{tabular}

As médias seguidas pela mesma letra minúscula na coluna não diferem estatisticamente entre si pelo Teste de Tukey ao nível de 5\% de probabilidade.

Analisando a Tabela 05, pode-se observar que a variedade NS5909 não diferiu significativamente nas variáveis de diâmetro caulinar, altura de planta e número de trifólios, já para as análises de dados de massa de 100 grãos, a densidade populacional foi um fator que afetou nos resultados positivos da presente pesquisa discordando de Cardoso \& Rezende (1987), no qual não encontraram diferenças na massa de grãos à variação do espaçamento. Para esta variedade o T4 (266 mil plantas.ha $\left.{ }^{-1}\right)$ superou estatísticamente o T2 (177 mil plantas.ha $\left.{ }^{-1}\right)$ o que pode estar atribuído à melhor distribuição do espaço e consequentemente melhor aproveitamento nutricional. 
Tabela 5 - Análise dos dados da cultivar NS5909, dados médios de diâmetro caulinar $(\mathrm{cm})$, altura de planta $(\mathrm{cm})$, número de trifólios, massa de 100 grãos $(\mathrm{g})$ e produtividade $\left(\mathrm{kg} \mathrm{ha}^{-1}\right)$ (umidade 13\%) conduzidos em sistema de semeadura direta. Adamantina, SP. 05 de fevereiro de 2019.

\begin{tabular}{lccccc}
\hline Avaliações & $\begin{array}{c}\text { Diâmetro } \\
\text { caulinar }\end{array}$ & $\begin{array}{c}\text { Altura de } \\
\text { planta }\end{array}$ & $\begin{array}{c}\text { Número de } \\
\text { trifólios }\end{array}$ & $\begin{array}{c}\text { Massa de } \\
\text { 100 grãos }\end{array}$ & Produtividade \\
\hline Teste F & 3,10 & 2,34 & 3,62 & $6,21^{*}$ & 4,15 \\
CV\% & 6,47 & 4,51 & 10,46 & 4,87 & 6,83 \\
D.M.S. & 1,12 & 4,54 & 5,15 & 1,77 & 212,97 \\
\hline T1 -6 & $7,59 \mathrm{a}$ & $46,25 \mathrm{a}$ & $25,25 \mathrm{a}$ & $16,36 \mathrm{ab}$ & $1.344,75 \mathrm{a}$ \\
T2 -8 & $7,94 \mathrm{a}$ & $46,00 \mathrm{a}$ & $21,00 \mathrm{a}$ & $15,32 \mathrm{~b}$ & $1.356,75 \mathrm{a}$ \\
T3 -10 & $7,50 \mathrm{a}$ & $43,25 \mathrm{a}$ & $20,25 \mathrm{a}$ & $16,46 \mathrm{ab}$ & $1.389,00 \mathrm{a}$ \\
T4 -12 & $8,49 \mathrm{a}$ & $46,75 \mathrm{a}$ & $22,75 \mathrm{a}$ & $17,75 \mathrm{a}$ & $1.556,50 \mathrm{a}$ \\
\hline
\end{tabular}

As médias seguidas pela mesma letra minúscula na coluna não diferem estatisticamente entre si pelo Teste de Tukey ao nível de 5\% de probabilidade.

Assim, pode-se observar que para algumas variedades, a densidade populacional de 12 plantas finais por metro linear apresenta melhores resultados em massa de 100 grãos e também em aspectos de produtividade. Neste sentido, considera-se que em determinadas cultivares de soja, a densidade populacional é um fator que interfere no desenvolvimento e produção final em determinados aspectos, tais como número de trifólio, altura de plantas e até mesmo o fator mais importante para a maioria dos produtores que é a produtividade de grãos.

Outro aspecto muito importante, sendo essencial para se obter sucesso na produtividade é conhecer o local implantação da sua lavoura, além da escolha do material genético adequado para a sua região e condição edafoclimática.

\section{CONCLUSÃO}

As variedades estudadas apresentam comportamentos distintos na a região da Alta Paulista; As variedades M5917, M7739 e NS5909 não apresentam diferença no potencial produtivo;

A cultivar PRECOZ expressa o seu melhor potencial produtivo com a população de 222 mil plantas. $\mathrm{ha}^{-1}$.

\section{REFERÊNCIAS}

BALBINOT JUNIOR A. A.et al. Espaçamento reduzido e plantio cruzado associados a diferentes densidades de plantas em soja. Semina: Ciências Agrárias, Londrina, v. 36, n. 5, p. 2977-2986, 2015

BONTO, E. R.; BONATO, A. L. V. A soja no Brasil: história e estatística. Londrina, EMBRAPACNPSo, 1987. 61p. (EMBRAPA-CNPSo. Documentos, 21)

CARDOSO, D. A. D. B.; REZENDE, P. M. de. Arranjo de plantas. I. Efeito do espaçamento e da densidade no rendimento de grãos e outras características da soja. Ciência e Prática, Lavras, v. 11, n. 1, p. 23-33, 1987. 
CIIAGRO. Estiagem e Seca. Disponível em: <

http://www.ciiagro.sp.gov.br/ciiagroonline/listagens/monagro/monagroatualedr.asp>. Acesso em: 02 abr. 2019.

EMPRESA BRASILEIRA DE PESQUISA AGROPECUÁRIA (EMBRAPA). Disponivel em: $<$ https://www.embrapa.br/soja/cultivos/soja>. Acesso em: 30 maio 2019.

EMPRESA BRASILEIRA DE PESQUISA AGROPECUÁRIA (EMBRAPA) Sistema Brasileiro de classificação de Solos. Centro Nacional de Pesquisa de Solos. Rio de Janeiro, 1999, 0412p.

EMPRESA BRASILEIRA DE PESQUISA AGROPECUÁRIA (EMBRAPA) Centro Nacional de Pesquisa de Soja (Londrina, PR). Recomendações técnicas para a cultura da soja na região central do Brasil: 1993/1994. Londrina, 1993. 120 p. (Documentos, 64).

MARCOS FILHO, J. Produção de sementes de soja. Campinas: Fundação Cargill, 1986. 86 p.

PEIXOTO, C. P. Análise de crescimento e rendimento de três cultivares de soja em três épocas de semeadura e três densidades de plantio. 1998. $151 \mathrm{f}$. Tese (Doutorado) - Escola Superior de Agricultura Luiz de Queiroz, Piracicaba.

PROCOPIO, S. O. et al. Semeadura em fileira dupla e espaçamento reduzido na cultura da soja. Agro@mbiente online, v.8, p.212-221, 2014.

TOURINO, M.C.C.; REZENDE, P.M. de; SALVADOR, N. Espaçamento, densidade e uniformidade de semeadura na produtividade e características agronômicas da soja. Pesquisa Agropecuária Brasileira, Brasília, v.37, n.8, p.1071-1077, ago.2002.

RAIJ, B. Van et al.Recomendações de adubação e calagem para o Estado de São Paulo. 2.ed. Campinas: IAC, 1997. 285p. (Boletim Técnico, 100) 